\title{
Drogas, Alimentos e corpos distintos: Problematizando éticas e estéticas da existência
}

\author{
Pablo Ornelas Rosa ${ }^{1}$ \\ Carlos Eduardo Gama ${ }^{2}$ \\ Yasmin Fernandes Sales dos Santos ${ }^{3}$
}

\begin{abstract}
Resumo: O artigo apresentado analisa os impactos promovidos pela classificação de um determinado produto como droga ou alimento, resultando em distintas formas de tratamento dado aos sujeitos que se encontram envolvidos com a produção, comércio e consumo dessas substâncias. Portanto, trata-se de ume reflexão acerca do conceito de drogas e alimentos e de que forma isso incide sobre os distintos sujeitos, produzindo tanto corpos-saudáveis, quanto corpos-criminosos e corpos-doentes, sendo estes dois últimos tratados ou a partir de uma perspectiva terapêutica ou pelo próprio sistema de justiça criminal. Ao analisar a imprecisão conceitual de alguns destes produtos a partir de um viés arbitrário e confuso estabelecido pela Agencia de Vigilância Sanitária - ANVISA, na medida em que o critério avaliado é o prejuízo causado pelo consumo de certas substâncias à saúde humana, propomos uma análise que problematiza a instrumentalização destes conceitos como técnicas de controle populacional decorrentes do estabelecimento de condutas supostamente normais, patológicas e criminais, característicos do contexto que a analítica foucaultiana chama de biopolítica.
\end{abstract}

Palavras-chave: Biopolítica, drogas, alimentos

\section{Drugs, Food and distinct bodies: Problematizing ethics and aeasthetics of existence}

Abstract: The article analyses the impact of the classification of certain
products as drug or food, resulting in differing ways to handle
subjects involved in the production, trading and consumption of those
substances. Therefore, it is a reflection on the concept of drug and
food and how this affects distinct subjects, producing

\footnotetext{
${ }^{1}$ Doutor em ciências sociais pela Pontifícia Universidade Católica de São Paulo - PUC/SP com estágio pós-doutoral em sociologia pela Universidade Federal do Paraná - UFPR, mestre em sociologia política e bacarel em ciências sociais pela Universidade Federal de Santa Catarina - UFSC. Atua como professor titular nos programas de mestrado em sociologia política e em segurança pública e coordena o Grupo de Pesquisa Subjetividade, Poder e Resistências - GESPOR na Universidade Vila Velha - UVV. Atualmente desenvolve estágio pós-doutoral em saúde coletiva na Universidade Federal do Espírito Santo - UFES.

${ }^{2}$ Carlos Eduardo Gama é graduado em história pela Universidade Federal do Espírito Santo - UFES e mestrando em sociologia política pela Universidade Vila Velha - UVV, além de ser integrante do Grupo de Pesquisa em Subjetividade, Poder e Resistências - GESPOR.

${ }^{3}$ Yasmin Fernandes Sales dos Santos é estudante do curso de graduação em psicologia pela Universidade Vila Velha - UVV, além de ser integrante do Grupo de Pesquisa em Subjetividade, Poder e Resistências GESPOR.
} 
N E P Revista NEP, Núcleo de Estudos Paranaenses, Curitiba, v.4, n.2, dez. 2018

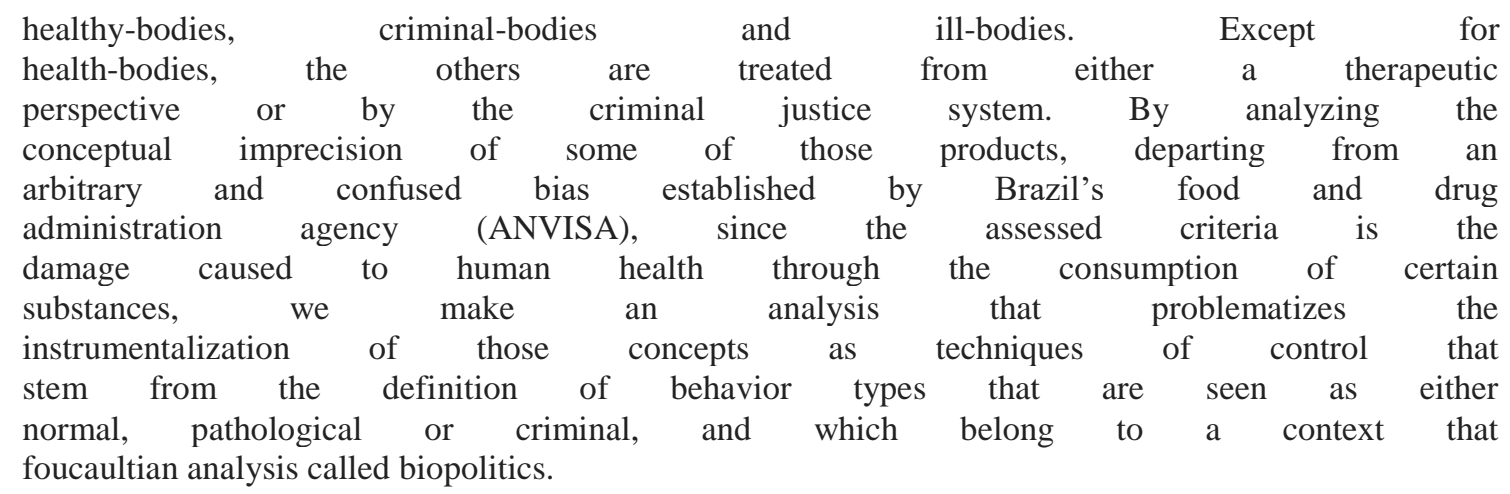

Key words: Biopolitic, drugs, foods.

\section{Contextualizando}

Se nos deparássemos com duas imagens distintas, sendo uma delas composta por um pimentão e um tomate e a outra com apenas uma folha da planta chamada cannabis, substância também conhecida vulgarmente por maconha, e fossemos questionados sobre quais delas deveríamos atribuir a condição de droga e alimento, provavelmente associaríamos o pimentão e o tomate a condição de alimento, assim como atribuiríamos a condição de droga à cannabis. Contudo, essa associação simplificada acaba por não considerar a complexidade de vários elementos imprescindíveis que deveríamos levar em consideração para proferirmos tais atribuições.

Nesse artigo, que resulta de uma apresentação na mesa "Estéticas Contemporâneas: Novos Corpos, Novas Éticas”, realizada no dia 17 de setembro de 2015 na Universidade Federal do Mato Grosso - UFMT, na ocasião do Seminário intitulado “Corpos, Consumo e Saúde: Reflexões Contemporâneas", procuramos debater sobre a complexidade que demarca a linha tênue entre a condição de droga e alimento, problematizando a produção de novas éticas e corporalidades provenientes das verdades engendradas pela relação entre saber e poder decorrente tanto de uma razão de Estado quanto de uma razão governamental, conforme ponderou Foucault (2008).

Segundo o autor francês, o Estado é um esquema de inteligibilidade de todo um conjunto de instituições já estabelecidas e dadas que opera como uma forma de 
intervenção ativa. Portanto, "o Estado é o que deve estar no fim da operação de racionalização da arte de governar" (Foucault, 2008: 385). Como a sua integridade, acabamento, fortalecimento e restabelecimento são obtidos através de uma razão que perpassa certo poder soberano, só é possível compreendermos o Estado por meio de seu princípio de inteligibilidade decorrente de seu objetivo estratégico que emoldura certa razão governamental.

A governamentalidade, que também pressupõe a incorporação e reprodução de certa racionalidade fundamentada na necessidade da existência do Estado, foi entendida por Foucault (2008) como um conjunto constituído por instituições, procedimentos, análises, reflexões, cálculos e táticas que permitiram o exercício dessa forma específica e complexa de poder que tem por alvo a população; por principal forma de saber a economia política; e por instrumento técnico essencial os dispositivos de segurança.

Como o Estado tem a população como objeto essencial na medida em que se utiliza de uma instrumentação de saber amparada na economia, pressupondo que o controle da sociedade ocorre por meio de dispositivos de segurança, a sua governamentalização acabou decorrendo de técnicas de governo que o permitiram sobreviver ao longo da história ocidental. Assim, “o Estado em sua sobrevivência e o Estado em seus limites só devem ser compreendidos a partir das táticas gerais da governamentalidade" (Foucault, 2008, p. 145).

(...) o Estado é, essencialmente e antes de mais nada, a idéia reguladora dessa
forma de pensamento, dessa forma de reflexão, dessa forma de cálculo, dessa
forma de intervenção que se chama política. A política como máthesis, como
forma racional da arte de governar. A razão governamental coloca o Estado,
portanto, como princípio de leitura da realidade o o coloca como objetivo e
como imperativo. O Estado é o que comanda a razão governamental, quer
dizer, é o que faz que se possa governar racionalmente segundo as
necessidades; é a função de inteligibilidade do Estado em relação ao real e é o
que faz que seja racional, que seja necessário governar. Governar
racionalmente porque há um Estado e para que haja um Estado (Foucault,
2008, p. 385-386).

Assim, será por meio de uma perspectiva foucaultiana que proporemos uma análise sobre a relação entre drogas e alimentos e como ela incide na governamentalização de certas verdades que produzem supostos corpos-saudáveis, corpos-drogados e corpos- 
criminosos. Todavia, dependendo da perspectiva de quem fala, essa atribuição poderá engendrar não somente situações-problema acerca das condutas desses sujeitos, como também poderá operar na captura de verdades produzidas por relações de saber/poder provenientes da associação entre Estado e mercado no contexto daquilo que Foucault chamou de biopolítica.

Antes de dar continuidade a essa apresentação, é imprescindível verificar que, para Foucault (2000), a atuação do poder absoluto derivado da soberania, que consistia em poder fazer morrer, foi perdendo cada vez mais espaço para uma tecnologia de biopoder fundamentado em um poder contínuo e científico perpetrado pelo poder de "fazer viver", que era exercido sobre a população e sobre o indivíduo enquanto ser vivo. Assim, enquanto o antigo poder soberano fazia morrer e deixava viver, essa nova tecnologia de poder de regulamentação chamada de biopolítica consistia em fazer viver e em deixar morrer.

Foucault (2010), em seus escritos dos anos 1970, constatou que a biopolítica de certa forma se hibridizou com a ascendente Teoria do Capital Humano, construída a partir do nascimento daquilo que o autor chamou de neoliberalismo americano, que acabou produzindo certo sujeito histórico do final de século XX e certamente presente no século XXI, chamado de homo æeconomicus.

\begin{abstract}
No neoliberalismo - e ele não esconde, ele proclama isso - também vai-se encontrar uma teoria do homo xeconomicus, mas como o homo æeconomicus, aqui, não é em absoluto um parceiro da troca. O homo xeconomicus é um empresário, e um empresário de si mesmo. Essa coisa é tão verdadeira que, praticamente, o objeto de todas as análises que fazem os neoliberais será substituir, a cada instante, o homo æeconomicus, parceiro da troca por um homo oconomicus empresário de si mesmo, sendo ele próprio seu capital, sendo para si mesmo seu produtor, sendo para si mesmo a fonte de [sua] renda (Foucault, 2010, p. 310-311).
\end{abstract}

Assim, essa relação entre fazer viver decorrente da emergente biopolítica, quando se hibridiza com Teoria do Capital Humano, acaba nos apresentando um problema um tanta quanto complexo: Como garantir o fazer viver, localizado por Foucault (1999), ao mesmo tempo em que emerge um novo sujeito histórico chamado de homo aconomicus que visa sempre obter ganhos? Contudo, o propósito dessa 
Revista NEP, Núcleo de Estudos Paranaenses, Curitiba, v.4, n.2, dez. 2018

apresentação será debater essa questão, sobretudo, no que se refere a relação entre alimento e droga, ponderando sobre os seus impactos na produção de corpos-saudáveis, corpos-drogados e corpos-criminosos decorrentes das verdades produzidas pela relação saber-poder que tem o Estado como legitimador dessa racionalidade neoliberal americana apontada por Foucault (2010).

Sendo assim, questionaremos a arbitrariedade da licitude e ilicitude acerca da atribuição da condição de droga e alimento a partir não somente de uma perspectiva etimológica e historiográfica, mas também a partir de suas consequências nos campos da saúde e da segurança pública que produzem racionalidades sobre os corpos daqueles que aderem determinadas comportamentos e condutas.

\section{Drogas ou alimentos?}

Em pesquisa realizada anteriormente (Rosa, 2014), localizamos a partir de Escohotado (1997), que existem dois tipos de substâncias que quando introduzidos em nossos corpos por quaisquer vias - oral, epidérmica, venosa, retal, intramuscular, subcutânea - podem ser assimiladas e convertidas em matéria para novas células, mesmo resistindo a uma assimilação imediata. É chamado de alimento tudo aquilo que introduzido em nosso corpo é assimilado de forma imediata, possibilitando a renovação e conservação de nossa condição orgânica. Entretanto, dentre as substâncias que não são assimiladas de imediato pelo nosso corpo distinguimos dois tipos básicos: aquelas que, como o cobre ou a maioria dos plásticos, por exemplo, são expulsas intactas sem exercer efeito algum sobre a massa corporal ou o estado de ânimo e aquelas que provocam uma intensa reação.

Estes segundos tipos são chamados de drogas e atuam de modo notável mesmo quando absorvidas em quantidades ínfimas se comparadas às quantidades de alimentos ingeridas diariamente. Todavia, ainda dentro deste grupo de substâncias é preciso distinguir os compostos que atuam somaticamente (como a cortisona, as sulfamidas ou a penicilina) e os que atuam não apenas somaticamente, mas que também provocam as nossas emoções, alterando nossos estágios de consciência. Estes últimos, considerados 
por diversas culturas antigas e modernas como milagrosos, são, em sua maioria, parentes carnais das substâncias que trocam mensagens com o sistema nervoso (os chamados neurotransmissores), recebendo o nome vulgar de drogas (Rosa, 2014).

Voltando ao exemplo apresentado inicialmente acerca das atribuições das condições de drogas ou alimentos decorrentes das imagens distintas do pimentão e tomate de um lado e da folha de cannabis de outro, verificamos que é possível problematizar e descontruir certas verdades acerca de sua produção resultante da relação saber/poder legitimado pelos Estados, mas capitaneado por empresas que operam a partir de interesses privados de mercado que visam o obtenção cada vez maior de lucros e/ou demais ganhos, conforme ponderou Foucault (2010) ao tratar da emergência da racionalidade neoliberal americana.

Como exemplo dessa relação entre a condição das drogas e alimentos produzidos por empresas privadas e seus consequentes lobbies pela regulamentação desses produtos, podemos citar a pesquisa realizada por Robin (2008) que resultou no livro e documentário intitulado "O Mundo Segundo a Monsanto". Nessa investigação, a autora mostrou os prejuízos causados pelas decisões políticas e não técnicas tomadas pelo governo estadunidense que trata da incorporação de agrotóxicos altamente prejudiciais à nossa saúde, isso sem falar das sementes orgânicas alteradas geneticamente com o propósito de trazer lucros e/ou demais ganhos através da cobrança de royalties pelos seus produtos alterados geneticamente, chamados de transgênicos.

Robin (2008) mostrou que parte dos agrotóxicos produzidos pela empresa estadunidense chamada Monsanto são comercializados sem a realização de pesquisas prévias que comprovem os seus impactos na saúde humana e animal. Ao desenvolver essa investigação, a autora constatou que alguns dos dirigentes dessa empresa não apenas fizeram lobbies com os governos estadunidense e canadense, como também atuaram como diretores da instituição responsável pela regulação de alimentos e drogas nos Estados Unidos, a Food and Drugs Administration - FDA. Ou seja, Robin (2008) constatou que as decisões acerca da autorização para a produção e comércio dessas substâncias que, conforme a autora, trazem enormes prejuízos à saúde, além de 
potencializar o câncer e provocar o chamado "deserto verde", foram tomadas a partir de um ponto de vista político e não técnico.

Ao tratar do caso brasileiro e sua agência similar à FDA estadunidense, a Agência Nacional de Vigilância Sanitária - ANVISA, Kedouk (2013) verificou que o Brasil consome uma quantidade consideravelmente alta de agrotóxicos, se comparado com grande parte dos países europeus. Segundo pesquisa apresentada pela autora, dos 18 alimentos pesquisados pela ANVISA no país, cinco deles têm metade ou mais das amostras com substâncias de uso proibido ou excesso de pesticidas como é o caso do pimentão $(91,8 \%)$, morango $(63,4 \%)$, pepino $(57,4 \%)$, alface $(54,2 \%)$, cenoura $(49,6 \%)$, dentre outros (Kedouk, 2013).

Não obstante, a grande parte dos governos ao redor do planeta, dentre eles o brasileiro, ainda apresentam como principal problema tanto de saúde quanto de segurança pública a questão do controle das drogas, entendendo esses produtos a partir de uma perspectiva arbitrária que não reflete necessariamente os benefícios ou prejuízos causados à saúde, embora seja esse o discurso que opere para garantir a circulação de certas substâncias psicoativas e a proibição de outras.

Se ponderarmos sobre a proibição trazendo questionamento mais complexos, certamente teremos a possibilidade de verificarmos em que contexto se articulam uma razão de Estado que reitera o discurso do mercado, fazendo operar tanto uma razão governamental circunscrita na produção de um corpo-saudável e supostamente isento de riscos, quanto um corpo-drogado no qual se atribui a condição patológica de desvio ou dependência química, assim como um corpo-criminoso, atualmente tido por grande parte da população brasileira como o grande inimigo da sociedade e responsável pela violência e demais males existentes na contemporaneidade. Assim, se a proibição das drogas resulta em uma guerra que mata muito mais do que as próprias substâncias, por que insistimos em proibir arbitrariamente alguns produtos e legalizar outros? O mercado da proibição não engendraria um aumento no valor dessas mercadorias, já que o risco eleva o seu preço?

Certamente, no contexto de capturas decorrente daquilo que Foucault (2010) chamou de biopolítica, passamos a governamentalizar certas verdades provenientes de 
relações entre saber e poder que dificultam ponderações que vão de encontro com os interesses do mercado uma vez que localizamos a também incidência de um poder disciplinar que desde a escola e demais processos de socialização nos faz crer em uma suposta neutralidade inquestionável da ciência moderna. Contudo, foi Foucault (2000) quem colocou em xeque essas verdades, mostrando como elas resultam de relações de força que pressupõe certos interesses questionáveis.

Ao reivindicar a urgência em se fazer "anti-ciência" através das busca pelos saberes sujeitados decorrente daquilo que chamou de arqueologia do saber, Foucault (2000) nos provocou a pensar de maneira genealógica não assumindo de antemão as verdades que são produzidas por certa ciência que resulta de interesses econômicos e que muitas vezes tem nos aparelhos estatais a condição de reféns para legitimar seus discursos, potencializando capturas que provocam a produção desses supostos corpossaudáveis, corpos-doentes e corpos-criminosos.

O mais interessante em se ponderar sobre essas produções, é pensar nas consequências e interesses econômicos que resultam delas e de seus eventuais mercados que visam garantir não apenas a segurança da população, mas sua normalização. Se um discurso de verdade sobre determinados alimentos produz novos mercados lucrativos que visam a produção de um corpo-saudável, por outro lado, ele também produz o corpodoente e sua eventual normalização através de uma economia política do tratamento, assim como produz uma economia política do crime e da pena resultante da atribuição da condição do corpo-criminoso que deve ser contido em prisões.

Portanto, quando falamos da produção da verdade tanto de uma perspectiva nietzschena quanto foucaultiana, estamos tratando de forças que resultam de embates entre saberes e poderes que, no contexto das atuais sociedades de normalização e segurança características da biopolítica, são estabelecidos de maneira arbitrária e a partir de certos interesses que visam instituir quais condutas devem ser aceitas, quais devem ser tratadas como doença e quais devem ser tratadas como crime, produzindo, respectivamente, corpos-saudáveis, corpos-doentes e corpos-criminosos. Não obstante, todos esses corpos passaram por um processo de docialização decorrente do exercício de um poder disciplinar legitimado por uma razão de Estado governamentalizada por um 
Revista NEP, Núcleo de Estudos Paranaenses, Curitiba, v.4, n.2, dez. 2018

poder soberano elaborador de políticas públicas a partir de interesses econômicos privados, característicos da racionalidade neoliberal americana dominante na contemporânea era da biopolítica.

Sendo assim, como é possível aceitarmos que os Estados ao redor do planeta proíbam a cannabis, que possui em sua semente a condição de um dos alimentos mais proteicos do mundo (Ribeiro; Malcher-Lopes, 2007), atribuindo a condição de droga ilícita e a responsabilizando pela grande parte dos males de nossa época, ao passo em que aceitam a onipresença de açúcar - substância extremamente prejudicial à saúde humana, conforme constatou Hyman (2014) -, na maior parte dos alimentos processados e comercializados no planeta. Ou seja, como é possível governamentalizarmos essa simplificação acerca do que é droga e do que é alimento, sem ponderarmos sobre os seus impactos na nossa vida e na daqueles que sofrem com as situações-problema resultantes dessa associação arbitrária?

Segundo Ribeiro e Malcher-Lopes (2007), a cannabis é uma das drogas recreativas mais usadas no mundo e está entre as mais antigas plantas domesticadas pelos humanos, tendo suas propriedades tanto curativas quanto terapêuticas presentes em escrituras sagradas e em documentos médicos das mais antigas e distintas culturas. Além disso, os autores rgumentam que dentre as mais de 3 milhões de plantas comestíveis que nascem em nosso planeta, nenhuma outra fonte vegetal é tão nutritiva quanto as sementes de cânhamo, considerada um super alimento.

Ribeiro e Malcher-Lopes (2007) localizaram no grego Heródoto, que viveu quatro séculos antes de Cristo, relatos sobre as qualidades terapêuticas da cannabis que incluíam o tratamento de distintas enfermidades, além de seu caráter proteico decorrente de suas propriedades alimentares. Segundo os autores, a mais antiga farmacopéia do mundo, Pent-Ts'ao Ching, escrita no primeiro século depois de Cristo mostra que a maconha era indicada para o tratamento de dores reumáticas, constipação, problemas femininos associado a mestruação, beribéri, gota, malária e falta de concentração. Não obstante, foi no incício do século XXI que pesquisadores verificaram que os canabinóides estão envolvidos na remodelação de circuitos neurais, na extinção de memórias traumáticas, na formação de novas memórias e na proteção de neurônios. Isso sem falar 
das descobertas realizadas um século atrás, que tratavam da desregulação do sistema canabióide envolvida nas causas da depressão, dependência psicológica, epilepsia, esquizofrenia e doença de Parkinson (Ribeiro e Malcher-Lopes, 2007).

A cannabis não apenas era considerada uma planta importante para a cultura popular do nordeste brasileiro entre os séculos XIX e XX, como também era uma mercadoria extremamente lucrativa nos agronegócios estadunidenses, tendo os presidentes Benjamin Franklin e Thomas Jefferson como dois de seus principais produtores, que utilizavam o óleo de cânhamo como combustível na produção da luz elétrica que chegava às ruas de algumas das grandes cidades dos Estados Unidos da América (Dória, 1986). Entretanto, o consumo da maconha no Brasil esteve constantemente associado à cultura negra e foram os seus estigmas e preconceitos associados a diplomacia estadunidense elaborada após a chamada Lei Seca, que acabaram orientando as políticas proibicionistas que incidem há décadas nas políticas de segurança pública do Brasil.

No final do século XIX, ascendia certa prática industrial que pretendia aproveitar ao máximo a força de trabalho, tendo como alvo o controle sobre as práticas sexuais, o higienismo e o consumo de drogas, inclusive do álcool. Foi em decorrência destas práticas providenciadas pelo Estado que surgiram as primeiras legislações proibicionistas nos Estados Unidos que criminalizavam o comércio e o consumo de ópio, cocaína e heroína (1914) e finalmente das bebidas alcoólicas, através da chamada Lei Seca de 1919 que, naquele país, durou até 1933 (Rosa, 2014).

A associação do consumo de substâncias psicoativas aos hábitos de determinadas minorias étnicas ocorria com frequência antes mesmo da elaboração das primeiras leis proibicionistas estadunidenses. Como naquela ocasião, os negros eram identificados como consumidores de cocaína; os chineses, como usuários de ópio; os irlandeses, como bebedores inveterados de álcool; os mexicanos, dentre outros hispânicos, como lascivos fumadores de maconha; a implantação de políticas, que buscassem controlar os corpos daqueles indivíduos pertencentes a certos grupos marginalizados, acabou se tornando uma realidade naquele país, que passou a vê-los 
Revista NEP, Núcleo de Estudos Paranaenses, Curitiba, v.4, n.2, dez. 2018

como perigosos inimigos internos e, portanto, associando os seus corpos ao crime ou à doenças que deveriam ser contidas (Rodrigues, 2004).

Como as classes mais abastadas também faziam uso dessas substâncias estabelecidas como ilícitas pelos governos, sua apreensão na condição de corpocriminoso passou a ser contestada e, a partir disso, passou-se a produzir o discurso da dependência química e de sua suposta condição de corpo-doente, visando a produção de certa seletividade criminal que atribuía uma condição patológica para uns e uma condição criminal para outros, dependendo de sua origem social e étnica, conforme podemos verificar nas políticas criminais brasileiras através do Mapa do Encarceramento (Brasil, 2015) e Diagnóstico de Pessoas Presas (Brasil, 2014), que apresentam o crime de tráfico de drogas como a segunda infração que mais resulta em aprisionamento no Brasil.

Contudo, essa seletividade criminal pode ser verificada nos mais variados estudos que dialogam com o campo do direito e suas vertentes menos normativas e dogmáticas como, por exemplo, a criminologia crítica (Baratta, 2002) e, mais recentemente, o abolicionismo penal (Hulsman; Celis, 1993), que têm mostrado a complexidade dessas relações que resultam na produção de corpos distintos que ou são capturados pelos discursos dos Estados e seus financiadores, o mercado, através da condição do suposto corpo-saudável, ou são encaminhandos para o tratamento em comunidades terapêuticas, programas de redução de danos e demais políticas públicas de saúde que visam normalizar os seus corpos, tornando-os produtivos e, portanto, incorporados pela sociedade como capital humano, assim como também podem ser destinados às prisões reais ou penas alternativas que garantam a impossibilidade de circularem pelas metrópoles, garantindo uma suposta condição de segurança coletiva.

\section{Considerações finais sobre a produção do corpo-saudável na era da biopolítica}

Ao tratarmos da produção legal e governamental do corpo-doente decorrente do consumo de drogas, sobretudo, as estabelecidas como ilícitas, e do corpo-criminoso, resultante da adesão de políticas que proíbem a produção e comércio dessas substâncias; 
Revista NEP, Núcleo de Estudos Paranaenses, Curitiba, v.4, n.2, dez. 2018

é possível verificarmos de que forma a droga aparece como um problema que deve ser contido através daquilo que Becker (2008) chamou de cruzada moral, capitaneado por empreendedores morais. As escolas têm exercido um papel extremamente negativo no que se refere ao debate sobre o controle das drogas na medida em que reproduz preconceitos fundamentados no senso comum e na normatividade legal, sem questionálos, conforme apontou Pretralonga (2015).

Além da preponderância do poder disciplinar que restringe a possibilidade de se produzir um sujeito crítico que seja ensinado a questionar verdades, localizando-as em campos de força, temos também o poder da sujeição e assujeitamento que operam a partir de uma razão governamental do qual somos capturados por verdades advindas da ciência moderna, como se os saberes produzidos por ela fossem isentos de elementos políticos construídos principalmente a partir de interesses econômicos. Sendo assim, a produção desse suposto corpo-saudável pode se dar também a partir de uma perspectiva exclusivamente discursiva e não material e/ou ontológica.

Quando nos dizem que maconha faz mal à saúde humana e que devemos comer carne porque a proteína oriunda dela é imprescindível para nossa saúde física - embora a própria construção da noção de saúde de um ponto de vista biopsicossocial estabelecido pela Organização Mundial da Saúde (2003), na prática, seja pouco utilizada pelos próprios profissionais da saúde -, estamos incorporando certo saber científico que tem sido legitimado pelos Estados sob forte influência política de interesses econômicos e privados de certas empresas que visam exclusivamente a obtenção lucros (Trichopoulos, Yen, Brown, Cole, MacMahon, 1984; Thorogood, Mann, Appleby, McPherson, 1994; Campbell, Chen, 1994). Isso também pode ser trazido para discutirmos a questão do açúcar e do glúten (Hyman, 2014), dentre outras drogas e/ou alimentos altamente prejudiciais para a nossa saúde física e que são comercializados livremente por todo o planeta, principalmente os transgênicos dos quais somos condicionados a aceitarmos em nossa alimentação cotidiana (Robin, 2008). Ou seja, estamos falando de alimentos que operam no nosso corpo sob a forma de drogas, ao passo que quando falamos da cannabis, por exemplo, estamos tratando de uma substância que pode ser incorporada pelo nosso corpo sob a condição de alimento, sendo um dos mais proteicos que conhecemos. 
Portanto, é imprescindível destacar que falar em drogas ou alimentos pressupõe a própria condição do sujeito que atribui essa valoração discursiva que muitas vezes não condiz com a realidade dos impactos desses produtos na saúde humana. Assim, a própria construção dessas categorias acaba nos condicionando a governamentalizarmos verdades que produzem classificações excludentes a partir da construção do corpo-doente e do corpo-criminoso, além de verificarmos que o discurso que opera a partir desse suposto corpo-saudável não condiz necessariamente com a saúde do sujeito, mas com os discursos produzidos por interesses econômicos privados que, através de lobbies e demais técnicas gerencialistas presentes nas estruturas institucionais dos Estados, acabam governamentalizando verdades fundamentadas na busca pela normalização de condutas que visam garantir a suposta segurança de seus corpos, procurando garantir a tão referendada "qualidade de vida", característica do fazer viver da nossa era da biopolítica.

\section{Referências}

ANTÓN, Danilo. El Concepto de "Drogas": Desinformación em Sociedades Consumidoras Periféricas. In: Cultura y Drogas, Manizales/Colômbia, N.13, 2006.

BARATtA, Alessandro. Criminologia Crítica e Crítica do Direito Penal. Rio de Janeiro: Ed. Revan, 2002.

BECKER, Howard. Outsiders. Rio de Janeiro: Jorge Zahar Editor, 2008.

BRASIL. Novo Diagnóstico de Pessoas Presas no Brasil. Brasília: Conselho Nacional de Justiça, 2014.

BRASIL. Mapa do Encarceramento: Os Jovens do Brasil. Brasília: Presidência da República e Secretaria Nacional de Juventude, 2015.

CAMPBELL, T. C.; CHEN, J. Diet and Chronic Degenerative Diseases: Perspectives From China. Am J Clin Nutr. 1994; 59: 1153S-1161S.

CARNEIRO, Henrique. Transformação do significado da palavra "droga": das especierias coloniais ao proibicionismo contemporâneao. In: VENÂNCIO, Renato Pinto; CARNEIRO, Henrique (org.). Álcool e Drogas na História do Brasil. Belo Horizonte: Ed. PUC-Minas, 2005. 
DERRIDA, Jacques. A Farmácia de Platão. São Paulo: Ed. Iluminuras, 2005.

DÓRIA, Rodrigues. Os Fumadores de Maconha: Efeitos e males do vício. In HENMAN, Anthony; PESSOA JUNIOR, Osvaldo (org.). Diamba Sarabamba: coletânea de textos brasileiros sobre a maconha. São Paulo: Ed. Ground, 1986.

HYMAN, Mark. 10 - Day Detox Diet. New York: Little, Brown and Company Group, 2014.

HULSMAN, Louk; CELIS, Jaqcueline Bernat de. Penas Perdidas. Niterói: Ed. Luam, 1993.

ESCOHOTADO, Antonio. O Livro das Drogas: Usos e abusos, desafios e preconceitos. São Paulo: Ed. Dynamis, 1997.

FOUCAULT, Michel. História da Sexualidade I: A Vontade de Saber. Rio de Janeiro: Ed. Graal, 1999.

FOUCAULT, Michel. Em Defesa da Sociedade. São Paulo: Ed. Martins Fontes, 2000.

FOUCAUlT, Michel. Segurança, Território, População. São Paulo: Ed. Martins Fontes, 2008.

FOUCAULT, Michel. Nascimento da Biopolítica. São Paulo: Martins Fontes, 2010.

KEDOUK, Márcia. Prato Sujo: Como a Indústria manipula os alimentos para viciar você. São Paulo: Ed. Abril, 2013.

MALCHER-LOPES, Renato; RIBEIRO, Sidarta. Maconha, Cérebro e Saúde. Rio de Janeiro: Ed. Vieira \& Lent, 2007.

ORGANIZAÇÃO MUNDIAL DA SAÚDE. Classificação internacional de funcionalidade, incapacidade e saúde. São Paulo: Edusp; 2003.

PRETRALONGA, Ilia C. Disciplinas e Normalizações nas Escolas: Estratégias de controle sobre as drogas por meio do empreendedorismo moral. Dissertação de Mestrado. Programa de Pós-Graduação em Sociologia Política - PPGSP. Universidade Vila Velha - UVV. Vila Velha, 2015.

ROBIN, Marie-Monique. O Mundo Segundo a Monsanto. São Paulo: Radical Livros, 2008.

RODRIGUES, Thiago M. S. Política e Drogas nas Américas. São Paulo: Ed. PUC/SP, 2004. 
ROSA, Pablo O. Drogas e a Governamentalidade Neoliberal: Uma Genealogia da Redução de Danos. Florianópolis: Ed. Insular, 2014.

THOROGOOD, M.; MANN, J.; APPLEBY, P.; MCPHERSON, K. Risk of Death From Cancer and Ischaemic Heart Disease in Meat and Non-Meat Eaters. Br Med J. 1994; 308:1667-1670.

TRICHOPOULOS, D.; YEN, S.; BROWN, J.; COLE, P.; MACMAHON, B. The Effect of Westernization on Urine Estrogens, Frequency of Ovulation, and Breast Cancer Risks: A Study in Ethnic Chinese Women in the Orient and in The U.S.A. Cancer. 1984; 53: 187-192.

Recebido: 10 set. 2018

Aceito: 16 nov. 2018 